\title{
Atom Probe Tomography of Feldspars and Aluminosilicate Glasses
}

\author{
Lyle M. Gordon
}

Environmental Molecular Spectroscopy Laboratory, Pacific Northwest National Laboratory, 3335 Innovation Blvd. Richland, WA 99354

Feldspars are a group of alumniosilicate minerals that make up as much as $60 \%$ of the Earth's crust. The most common feldspars can be expressed in terms of three endmembers (Figure 1), specifically, potassium feldspar (Orthoclase), sodium feldspar (Albite) and Calcium feldspar (Anorthite). At high temperatures, solid solutions exist between the distinct endmembers; however, during cooling miscibility gaps result in phase separation (exsolution) of the solid solution into multiple stable phases.

The phase separation and the formation of the resulting microstructure could occur either by nucleation and growth of a second phase or by spinodal decomposition, both followed by coarsening. Identifying the phase transformation and microstructure formation mechanisms and determining the geological history of these materials requires detailed analysis of the microstructure and quantitative compositional measurements of the exsolved phases. To characterize the fine length scale of the microstructure and limited degree of chemical variation simultaneously, an analytical tool with high spatial resolution and chemical sensitivity is required.

Atom-probe tomography (APT) is uniquely capable of characterizing the nanoscale chemistry of the exsolution microstructure. APT is an established technique in metallurgical and semiconductor research, however, with the recent advent of ultra-violet laser pulsing analysis of a range of minerals has become possible, however, only a few have been analyzed to date including iron oxides [1], apatites [2], and olivines [3].

Initial results from atom probe tomographic investigation into the structure and chemistry of natural and synthetic alkali and plagioclase feldspars of varied compositions and microstructures will be presented. Both stable endmembers and unstable compositions within the miscibility gap have been analyzed (Figure 1 \& 2). APT mass-to-charge ratio spectra (Figure 2) demonstrated high spectral resolution, $\Delta \mathrm{m} / \mathrm{m}$, of greater than 1000 at full width-half max of the $\mathrm{Si}^{2+}$ peak. Runs with greater than $10^{7}$ ions were routinely collected with reliable detection of trace ions below $100 \mathrm{ppm}$. Analytical results under a range of experimental conditions to determine the ideal operating parameters for APT of feldspars will be presented. Further, comparison of data from crystalline feldspars minerals to compositionally similar glassy materials will be conducted to identify the influence of crystallinity on APT.

[1] Gordon L. M. \& Joester D. Nanoscale chemical tomography of buried organic-inorganic interfaces in the chiton tooth. Nature 469 (2011) p .194-197.

[2] Gordon L.M., Tran L., \& Joester D. Atom probe tomography of apatites and bone-type mineralized tissues. ACS nano 6 (2012) p. 10667-10675.

[3] Arey, B. et al. Atom Probe and TEM Investigation of Natural Olivines. Microscopy and Microanalysis. 18 S2 (2012) p. 658-659.

[4] The research was performed using EMSL, a DOE Office of Science User Facility sponsored by the Office of Biological and Environmental Research and located at Pacific Northwest National Laboratory. 


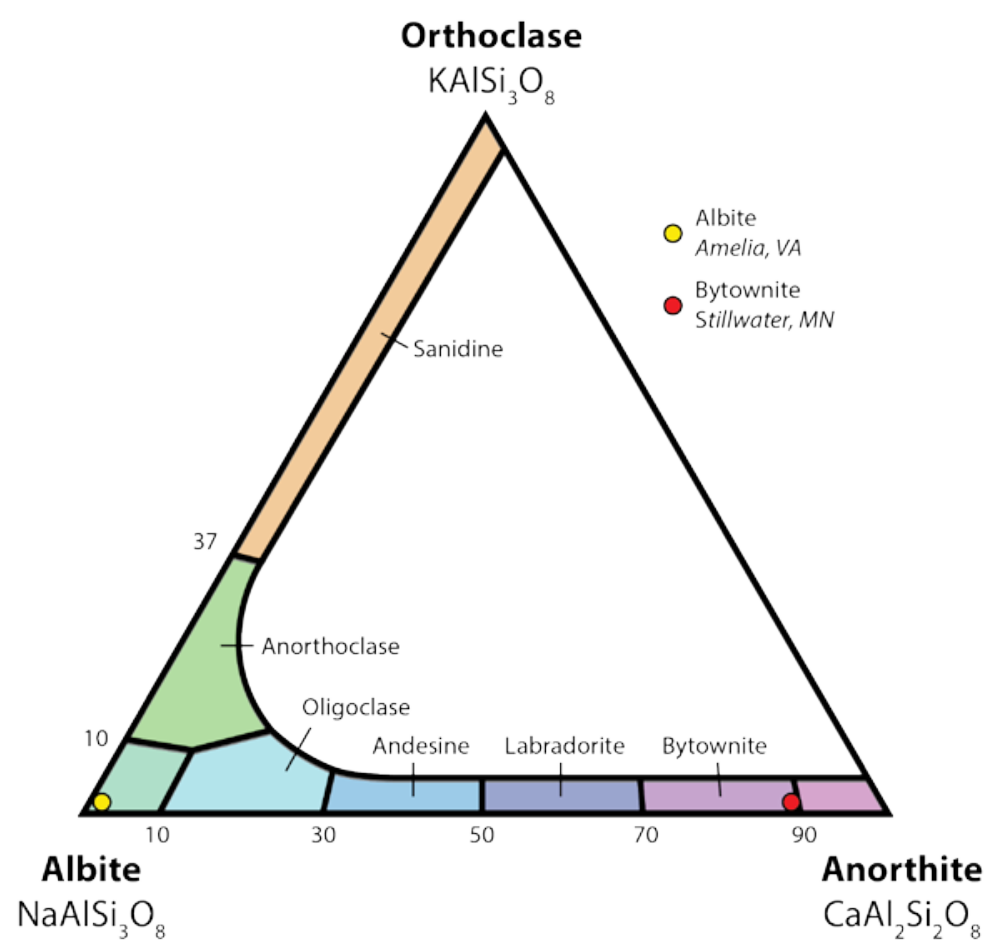

Figure 1. Ternary phase diagram of feldspar. Endmember and solids-solution (not necessarily stable) are labeled with mineralogical names. Composition and locality of analyzed samples (Albite, yellow circle and Bytownite, red circle) are indicated on the diagram.

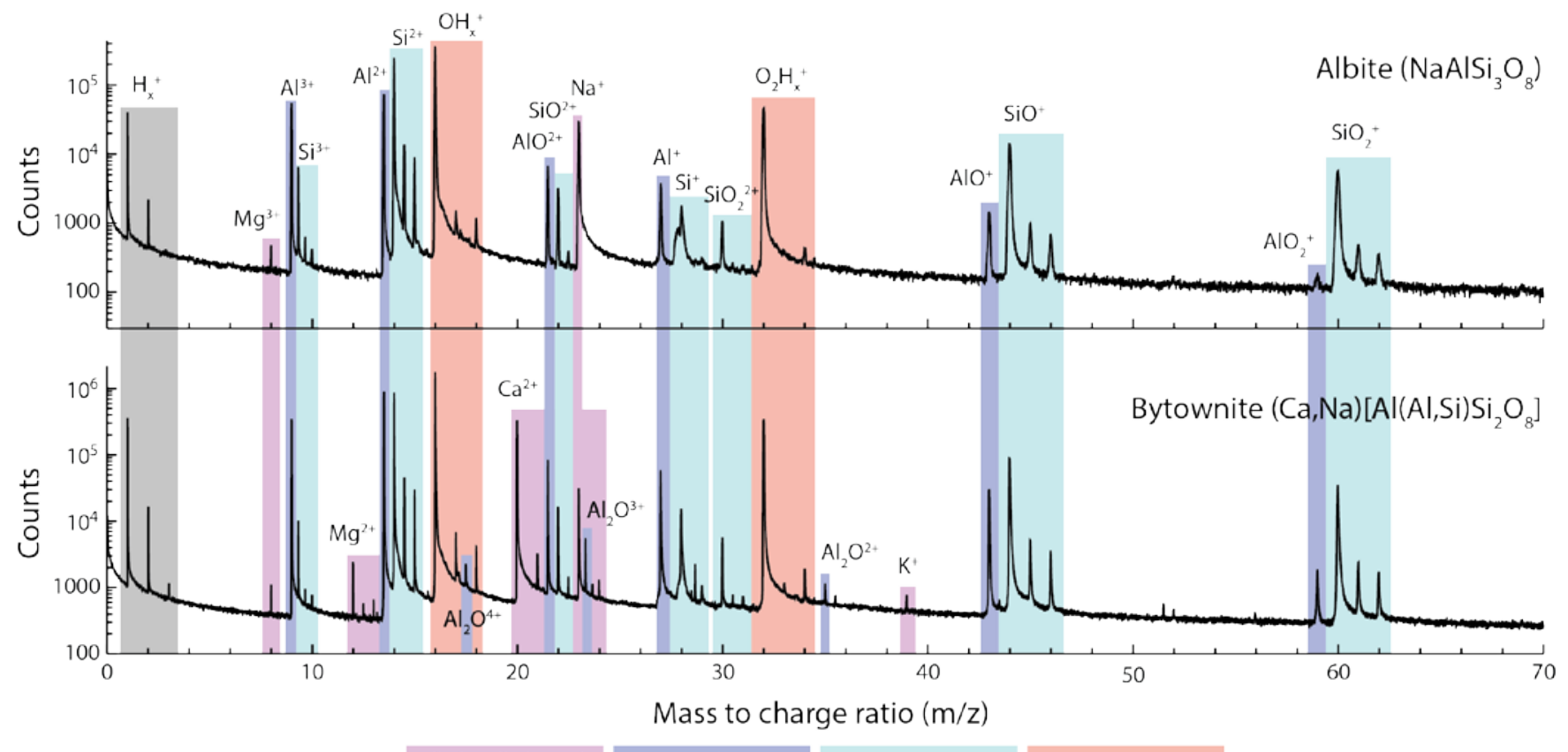

Alkali / Alkali Earth

$\mathrm{Al}$

Si

O

Figure 2. Labeled atom probe mass-to-charge state ratio spectra for representative samples of Amelia Albite and Stillwater Bytownite, corresponding to the points indicated in Figure 1. 